\title{
Circulating dipeptidyl peptidase-3 at admission is associated with circulatory failure, acute kidney injury and death in severely ill burn patients
}

François Dépret ${ }^{1,2,3}$, Juliette Amzallag ${ }^{1}$, Adrien Pollina ${ }^{1}$, Laure Fayolle-Pivot ${ }^{4}$, Maxime Coutrot ${ }^{1,2}$, Maïté Chaussard ${ }^{1}$, Karine Santos ${ }^{5}$, Oliver Hartmann ${ }^{5}$, Marion Jully', Alexandre Fratani ${ }^{1}$, Haikel Oueslati ${ }^{1}$, Alexandru Cupaciu', Mourad Benyamina ${ }^{1,2}$, Lucie Guillemet ${ }^{1}$, Benjamin Deniau ${ }^{1,2,3}$, Alexandre Mebazaa ${ }^{1,2,3}$, Etienne Gayat ${ }^{1,2,3}$, Boris Farny ${ }^{4,6}$, Julien Textoris ${ }^{4,6}$, Matthieu Legrand ${ }^{1,2,3,7^{*}}$ and for the PRONOBURN group

\begin{abstract}
Background: Dipeptidyl peptidase-3 (DPP3) is a metallopeptidase which cleaves bioactive peptides, notably angiotensin II, and is involved in inflammation regulation. DPP3 has been proposed to be a myocardial depressant factor and to be involved in circulatory failure in acute illnesses, possibly due to angiotensin II cleavage. In this study, we evaluated the association between plasmatic DPP3 level and outcome (mortality and hemodynamic failure) in severely ill burn patients.
\end{abstract}

Methods: In this biomarker analysis of a prospective cohort study, we included severely ill adult burn patients in two tertiary burn intensive care units. DPP3 was measured at admission (DPP3 ${ }_{\text {admin }}$ ) and 3 days after. The primary endpoint was 90-day mortality. Secondary endpoints were hemodynamic failure and acute kidney injury (AKI).

Results: One hundred and eleven consecutive patients were enrolled. The median age was 48 (32.5-63) years, with a median total body surface area burned of 35\% (25-53.5) and Abbreviated Burn Severity Index (ABSI) of 8 (7-11). Ninety-day mortality was $32 \%$. The median DPP3admin was significantly higher in non-survivors versus survivors (53.3 ng/mL [IQR 28.8-103.5] versus $27.1 \mathrm{ng} / \mathrm{mL}$ [IQR 19.4-38.9]; $p<0.0001)$. Patients with a sustained elevated DPP3 had an increased risk of death compared to patients with high DPP3 admin but decreased levels on day 3. Patients with circulatory failure had higher DPP3 admin $(39.2 \mathrm{ng} / \mathrm{mL}$ [IQR 25.9-76.1] versus $28.4 \mathrm{ng} / \mathrm{mL}$ [IQR 19.8-39.6]; $p=$ $0.001)$ as well as patients with AKI (49.7 ng/mL [IQR 30.3-87.3] versus $27.6 \mathrm{ng} / \mathrm{mL}$ [IQR 19.4-41.4]; $p=0.001)$. $\mathrm{DPP}_{\text {admin }}$ added prognostic value on top of ABSI (added $\mathrm{chi}^{2} 12.2, p=0.0005$ ), Sequential Organ Failure Assessment (SOFA) score at admission (added $\mathrm{chi}^{2} 4.9, p=0.0268$ ), and plasma lactate at admission (added chi ${ }^{2}$ 6.9, $p=0.0086)$ to predict circulatory failure within the first $48 \mathrm{~h}$.

(Continued on next page)

\footnotetext{
* Correspondence: matthieu.legrand@ucsf.edu

'Department of Anesthesiology and Critical Care and Burn Unit, AP-HP, GH

St-Louis-Lariboisière, Paris, France

${ }^{2}$ University Paris Diderot, Paris, France

Full list of author information is available at the end of the article
}

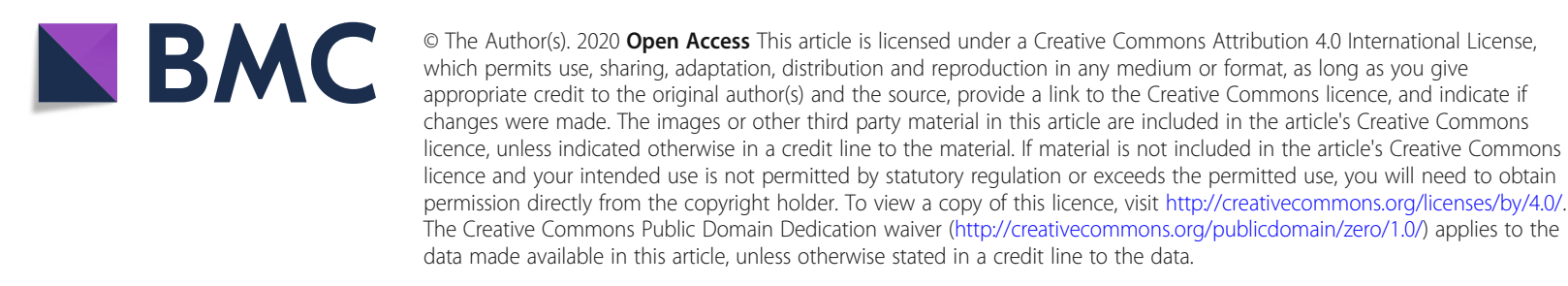


(Continued from previous page)

Conclusions: Plasma DPP3 concentration at admission was associated with an increased risk of death, circulatory

failure, and AKI in severely burned patients. Whether DPP3 plasma levels could identify patients who would

respond to alternative hemodynamic support strategies, such as intravenous angiotensin II, should be explored.

Keywords: Dipeptidyl peptidase-3, Burn patients, Mortality, Acute kidney injury, Biomarkers

\section{Background}

Severe burn injury is associated with an early and profound hypovolemia followed by an intense systemic inflammatory response. Hemodynamic management, including fluid resuscitation, has long been recognized as the cornerstone of the early management and hemodynamic resuscitation of severely burned patients [1-3]. However, a systemic inflammatory response may be associated with distributive shock and/or acute myocardial dysfunction [4]. Dipeptidyl peptidase-3 (DPP3), also named enkephalinase B or red cell angiotensinase, is a predominantly intracellular, ubiquitously expressed, zinc-dependent metallopeptidase involved in the metabolism of peptides [5] implicated in many different pathways (e.g., blood pressure regulation, inflammation). DPP3 cleaves bioactive peptides, notably angiotensin II, enkephalins, and endomorphins [6-8]. We hypothesize that cleavage of angiotensin II by DPP3 may promote vasodilatation and circulatory failure. Severe burn patients are at high risk of developing vasodilatory shock with systemic inflammatory response after the early phase of hypovolemic shock. The main objective of this study was therefore to assess the association between DPP3 at admission (DPP3 $\left.{ }_{\text {admin }}\right)$ and day 3 (DPP3 $\left.3_{\text {Day3 }}\right)$ with 90-day mortality in severely burned patients. The secondary objective was to evaluate the association between DPP3 and organ dysfunction (i.e., circulatory failure and acute kidney injury (AKI)).

\section{Methods}

\section{Study design and population}

We conducted a double-center cohort study in the Burn Unit of Saint Louis Hospital (Assistance Publique Hôpitaux de Paris), Paris, and in the Burn Unit of Edouard Herriot Hospital, Lyon, France. The study was approved by our local ethic committee (PRONOBURN study, comité de protection des personnes IV, St-Louis Hospital; Institutional Review Board 00003835, protocol 2013/17NICB). All patients admitted to our intensive care burn units (ICBU) between April 2014 and April 2016 and meeting the inclusion criteria were included. Inclusion criteria were the following:

- A total body surface area [TBSA] burned $>15 \%$

- Admission in the ICBU within the $72 \mathrm{~h}$ following burn injury
- No decision to withdraw life support

- Available plasma sample at admission

\section{Outcome}

The endpoints were 90-day mortality, circulatory failure in the first $48 \mathrm{~h}$, and AKI.

\section{Measurements}

The following data have been collected: sex, age, body mass index (BMI), TBSA, full-thickness body surface area (BSA) burned, mechanism of injury and patients' characteristics, Abbreviated Burn Severity Index (ABSI) [9], Unit Burn Standard (UBS) [10], Sequential Organ Failure Assessment (SOFA) score [11], 28- and 90-day mortality, and AKI. Patients were resuscitated according to the Intensive Care Burn Unit resuscitation protocol [12]. A transthoracic or transesophageal echocardiography was performed at admission of patients according to the decision of the physician in charge. When performed, left ventricular ejection fraction (LVEF) was visually evaluated and systolic cardiac dysfunction was defined by a LVEF $<50 \%$ [13]. Circulatory failure was defined as a need for hemodynamic support with inotrope and/or a vasopressor (i.e., dobutamine, epinephrine, or norepinephrine) despite appropriate fluid resuscitation in the first $48 \mathrm{~h}$. We choose this time frame to identify circulatory failure related to burn injury (as opposed to sepsis or surgical procedures which occur later during the course of burn injuries). AKI was defined and staged according to the Kidney Disease: Improving Global Outcomes (KDIGO) criteria [14] during the first 7 days post admission. Admission serum creatinine e (Screat $\left.{ }_{\text {admin }}\right)$ was used as baseline Screat.

Venous blood samples were collected at admission and at day 3 in tubes containing ethylene-diamine-tetra-acetic acid. After centrifugation, plasma was kept frozen at $80^{\circ} \mathrm{C}$ until assayed. DPP3 was measured using the recently developed DPP3 luminescence immunoassay [15].

\section{Statistical analysis}

Values are expressed as medians and interquartile ranges (IQR) or counts and percentages as appropriate. Group comparisons of continuous variables were performed using Kruskal-Wallis test. Categorical data were compared using Pearson's chi-squared test for count data. DPP3 data was log-transformed. Cox proportional- 
hazards regression was used to analyze the effect of risk factors on survival in uni- and multivariable analyses, and logistic regression was used for dichotomous endpoints. In both cases, to demonstrate independence from other variables, the added value of DPP3 on top of these was evaluated based on the likelihood ratio chi-squared test for nested models. The concordance index ( $\mathrm{C}$ index or AUC) is given as an effect measure for uni- and multivariable models. For multivariable models, a bootstrapcorrected version of the $\mathrm{C}$ index is given. For continuous variables, hazard ratios (HR) or odds ratios (OR), as appropriate, were standardized to describe the HR/OR for a change of one IQR. HR (Cox regression) are used if time-to-event data is available; OR (logistic regression) are used if endpoints have event data (yes/no) only. Survival curves plotted by the Kaplan-Meier method were used for illustrative purposes. For dichotomous endpoints, receiver operating characteristic (ROC) curves were constructed for illustration. All statistical tests were 2-tailed and a two-sided $p$-value of 0.05 was considered for significance. The statistical analyses were performed using $\mathrm{R}$ version 3.4.3 (http://www.r-project.org, library rms, Hmisc, ROCR) and Statistical Package for the Social Sciences (SPSS) version 22.0 (SPSS Inc., Chicago, Illinois, USA).

\section{Results}

\section{Study population}

From April 2014 to April 2016, 208 consecutive patients met the inclusion criteria; 55 patients had missing plasma at admission and were not included in the final analysis, resulting in 111 patients that were analyzed. The characteristics of the patients included in this study are summarized in Table 1 . The median age was 48 (32.5-63) years, with a median TBSA of 35\% (25-53.5) and median ABSI of $8(7-11)$. All patients had a DPP $3_{\text {ad- }}$ min measurement and 79 patients $(71 \%)$ had DPP $3_{\text {Day3 }}$ (10 patients died before day 3 and 22 patients had missing measurements at day 3 ).

\section{DPP3 $3_{\text {admin }}$ and 90-day mortality}

Thirty-six (32\%) patients died before day 90. Median $\mathrm{DPP}_{\text {admin }}$ was significantly higher in non-survivors versus survivors $(53.3 \mathrm{ng} / \mathrm{mL}$ [IQR 28.8-103.5] versus 27.1 $\mathrm{ng} / \mathrm{mL}$ [IQR 19.4-38.9]; $p<0.0001$ ). We observed a stepwise increase in mortality among quartile groups of $\mathrm{DPP}_{\mathrm{admin}}$, the patients in the highest quartile having the highest mortality (Fig. 1). There was no interaction between DPP3 value and TBSA $(p=0.7132)$ (Supplementary Figure 1 ). The $\mathrm{C}$ index of $\mathrm{DPP} 3_{\text {admin }}$ for 90 -day mortality was $0.734(0.653-0.815, p<0.0001$, standardized HR 2.6 (1.9-3.6)). DPP3 ${ }_{\text {admin }}$ added prognostic value on top of ABSI (added $\mathrm{chi}^{2} 24.5, p<0.0001$ ), SOFA score at admission $\left(\mathrm{SOFA}_{\mathrm{admin}}\right.$, added $\mathrm{chi}^{2}$ 15.4, $p<$
0.0001), and lactate at admission (added $\operatorname{chi}^{2}$ 11.7, $p=$ 0.0006 ) to predict 90-day mortality (Fig. 2). Furthermore, adding DPP3 $3_{\text {Day3 } 3}$ to DPP3 $3_{\text {admin }}$ provided added value to predict 90-day mortality (added $\mathrm{chi}^{2} 5.6, p=0.018$; missing data at day 3 replaced with admission data). Patients with a high DPP $3_{\text {admin }}$ that decreased at day 3 had a better prognosis than patients with high DPP $3_{\text {admin }}$ and sustained DPP3 $3_{\text {Day3 }}$ (Fig. 3).

\section{DPP3 and circulatory failure}

Fifty-three $(48 \%)$ patients had circulatory failure during the first $48 \mathrm{~h}$ (44 patients received norepinephrine, five patients received dobutamine + norepinephrine, 4 patients received epinephrine). DPP $3_{\text {admin }}$ was significantly higher in patients with circulatory failure compared to patients without $(39.2 \mathrm{ng} / \mathrm{mL}$ [IQR 25.9-76.1] versus $28.4 \mathrm{ng} / \mathrm{mL}$ [IQR 19.8-39.6]; $p=0.001$ ) (Fig. 4 left panel). DPP3 $3_{\text {admin }}$ was associated with circulatory failure with an AUC of $0.680(0.581-0.778, p<0.0001$, standardized OR 2.8 (1.6-4.9)). DPP3 $3_{\text {admin }}$ provided value on top of ABSI (added chi ${ }^{2} 12.2, p=0.0005$ ), SOFA score at admission $\left(\mathrm{SOFA}_{\text {admin }}\right.$, added $\left.\mathrm{chi}^{2} 4.9, p=0.0268\right)$, and lactate at admission (added $\mathrm{chi}^{2} 6.9, p=0.0086$ ) to predict hemodynamic support in the first $48 \mathrm{~h}$. There was no correlation between DPP3 and the volume administered on day $1(r=0.17, p=0.07)$.

Fifty-nine patients (53\%) had an echocardiography performed at admission. Among them, 10 (17\%) patients had a systolic cardiac dysfunction. DPP $3_{\text {admin }}$ was significantly higher in patients with systolic cardiac dysfunction compared to patients without $(62.4 \mathrm{ng} / \mathrm{mL}$ [IQR 40.4-112.3] versus $29.3 \mathrm{ng} / \mathrm{mL}$ [IQR 22.4-45.1]; $p<$ 0.0122) (Fig. 4 middle panel). The area under the ROC curve for DPP $3_{\text {admin }}$ to predict systolic cardiac dysfunction was $0.753(95 \%$ CI $0.582-0.925, p=0.0054)$.

\section{DPP3 and acute kidney injury}

Thirty-five (32\%) patients developed AKI during the first 7 days. DPP $3_{\text {admin }}$ was significantly higher in patients with AKI compared to patients without $(49.7 \mathrm{ng} / \mathrm{mL}$ [IQR 30.3-87.3] versus $27.6 \mathrm{ng} / \mathrm{mL}$ [IQR 19.4-41.4]; $p=$ $0.001)$ (Fig. 4 right panel). DPP $3_{\text {admin }}$ was associated with AKI with an AUC of 0.735 (0.641-0.829, $p=0.0005$, standardized OR $2.3(1.4-4.0))$. DPP 3 admin added value on top of ABSI (added $\mathrm{chi}^{2}$ 9.4, $p=0.0022$ ), SOFA score at admission ( $\mathrm{SOFA}_{\mathrm{admin}}$, added $\mathrm{chi}^{2}{ }^{2} 14.3, p=0.0002$ ), but not on top of creatinine at admission (added chi ${ }^{2}$ $0.3, p=0.5954)$ to predict AKI.

\section{Discussion}

In this biomarker analysis of a prospective cohort, we observed that DPP3 $3_{\text {admin }}$ was strongly associated with 90-day mortality, circulatory failure, and AKI in severely burned patients. Furthermore, adding $\mathrm{DPP}_{\text {admin }}$ to 
Table 1 Patients characteristics

\begin{tabular}{|c|c|c|c|c|}
\hline Patient's characteristics & Total, $\boldsymbol{N}=111$ & 90-day survivors, $\boldsymbol{N}=75$ & 90-day non-survivors, $\boldsymbol{N}=36$ & $p$ \\
\hline Sex, male-n (\%) & $71(64)$ & $51(68)$ & $20(56)$ & 0.2858 \\
\hline Age-year & $48[32.5-63]$ & $42[29-58]$ & $56.5[42-79]$ & 0.0013 \\
\hline $\mathrm{BMI}-\mathrm{kg} / \mathrm{m}^{2}$ & $25.2[22.9-28.7]$ & $25.1[23-28.3]$ & $25.7[22.4-29.1]$ & 0.9673 \\
\hline \multicolumn{5}{|l|}{ Medical history } \\
\hline $\mathrm{ClC}-n(\%)$ & $3(2.7)$ & $2(3)$ & $1(3)$ & 1.0000 \\
\hline COPD-n (\%) & $3(2.7)$ & $2(3)$ & $1(3)$ & 1.0000 \\
\hline CKD-n $(n)$ & $5(4.5)$ & $1(1)$ & $4(11)$ & 0.0374 \\
\hline Chronic HBP-n (\%) & $25(22.5)$ & $12(16)$ & $13(36)$ & 0.0277 \\
\hline Psychiatric —n (\%) & $34(30.6)$ & $22(29)$ & $12(33)$ & 0.6668 \\
\hline \multicolumn{5}{|l|}{ Burn characteristics } \\
\hline TBSA—\% & $35[25-53.5]$ & $32[22-45]$ & $57[31-70]$ & $<0.0001$ \\
\hline Deep burn BSA—\% & $21[10-40]$ & 17 [7-30] & $42[15-61]$ & 0.0001 \\
\hline Inhalation injury—n (\%) & $54(48.6)$ & $28(37)$ & $26(72)$ & 0.0012 \\
\hline \multicolumn{5}{|l|}{ Characteristics during hospitalization } \\
\hline Mechanic ventilation—n (\%) & $82(73.9)$ & $52(69)$ & $30(83)$ & 0.1799 \\
\hline $\mathrm{DPP}_{\mathrm{admin}}(\mathrm{ng} / \mathrm{mL})$ & $30.6[22.4-53.6]$ & $27.1[19.4-40.2]$ & $53.3[29.5-104]$ & $<0.0001$ \\
\hline $\mathrm{DPP}_{\text {day3 }}(\mathrm{ng} / \mathrm{mL})$ & $17.3[11.8-25.2]$ & $14.1[11.5-20.6]$ & $22.1[16.6-30.8]$ & 0.0102 \\
\hline Screat- $\mu \mathrm{mol} / \mathrm{L}$ & $72.5[56.5-92]$ & $70[54.8-81.3]$ & $90.5[67.3-138.3]$ & 0.0003 \\
\hline Lactate-mmol/L & $3.5[2.0-5.7]$ & $2.7[1.7-4.6]$ & $5.2[3.5-8]$ & $<0.0001$ \\
\hline Bilirubin-mmol/L & $14.0[9.3-21.3]$ & $12.9[9-19.3]$ & 18 [10.9-25.9] & 0.0945 \\
\hline Platelet-G/L & 250 [185-304] & $236[183-277]$ & 279 [180-372] & 0.3840 \\
\hline Length of hospitalization—days & 90 [35.5-90] & $41[26-61]$ & $18[2-32.5]$ & $<0.0001$ \\
\hline RRT-n (\%) & $24(21.6)$ & $5(7)$ & $28(78)$ & $<0.0001$ \\
\hline \multicolumn{5}{|l|}{ Severity scores } \\
\hline SOFA & $4[1-7]$ & $2[0-4]$ & $6.5[3.3-9.8]$ & $<0.0001$ \\
\hline ABSI & $8[7-11]$ & $8[6-9]$ & $11[9-13]$ & $<0.0001$ \\
\hline SAPS2 & $33[23-47]$ & $28[20-42]$ & $47[33-62]$ & $<0.0001$ \\
\hline UBS & $100[52.5-166]$ & 84 [45-132] & 184 [86-249] & $<0.0001$ \\
\hline \multicolumn{5}{|l|}{ Hemodynamic on admission } \\
\hline Echocardiography, n (\%) & $59(53)$ & $33(44)$ & $26(72)$ & 0.0078 \\
\hline Systolic cardiac dysfunction, $n$ (\%) & $10(9)$ & $2(3)$ & $8(22)$ & 0.0163 \\
\hline Circulatory failure, $n(\%)$ & $53(48)$ & $24(32)$ & $29(81)$ & $<0.0001$ \\
\hline MAP in $\mathrm{mmHg}$ & 79 [70-95] & 84 [73-97] & 73 [64-85] & 0.0104 \\
\hline Volume of crystalloids at day 1 & $8250[3700-15,000]$ & $6700[3300-12,800]$ & $13,400[6430-18,380]$ & 0.0018 \\
\hline Volume of crystalloids at day 2 & $3000[1000-5650]$ & 2500 [1000-5150] & $4000[2000-7500]$ & 0.1078 \\
\hline
\end{tabular}

$B M I$ body mass index, $C I C$ chronic ischemic cardiopathy, COPD chronic obstructive pulmonary disease, CKD chronic kidney disease, $H B P$ high blood pressure, $T B S A$ total burn surface area, ECMO extracorporeal membrane oxygenation, Screat serum creatinine at admission, $R R T$ renal replacement therapy, SOFA score simplified organ failure assessment, ABSI Abbreviated Burn Severity Index, UBS Unit Burn Standard, SAPS 2 The Simplified Acute Physiology Score

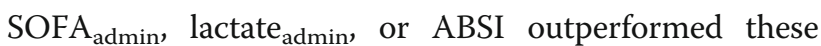
prognostic factors to predict 90-day mortality. Serial measurements of DPP3 have improved the prediction of outcome compared to DPP $3_{\text {admin }}$ alone.

While the prognosis of burn patients has improved, the mortality of most severe patients remains high with many patients dying from circulatory failure and multiple organ failure $[16,17]$. Initial hemodynamic management has long been considered critical in the treatment and prognosis of burn patients [18]. Burn injury is characterized by an initial hypodynamic state with low cardiac output due to hypovolemia followed by a hyperdynamic state with high cardiac output and low vascular resistance developing 12 to $24 \mathrm{~h}$ after the injury [1]. The severity of the distributive shock and occurrence of cardiac dysfunction may, however, vary greatly between 


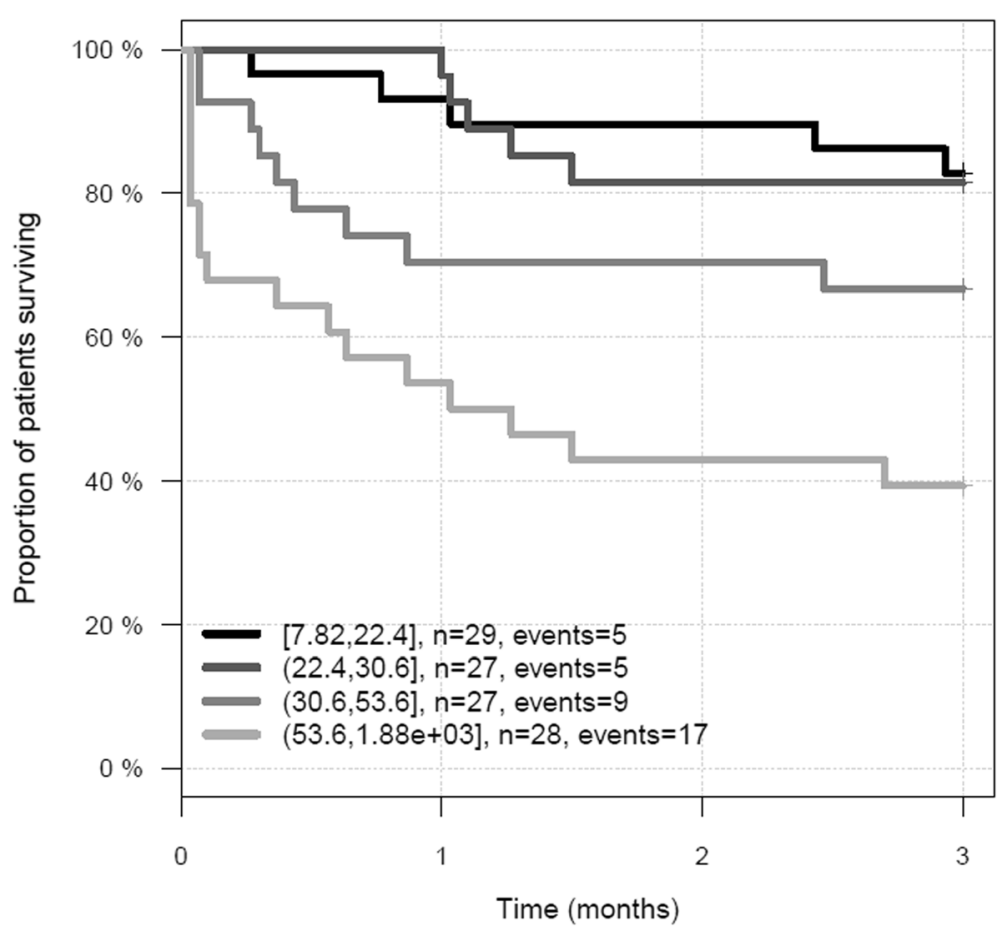

Fig. 1 Represents a survival Kaplan-Meier curve depending on DPP3 admin quartiles (legend gives quartile ranges for DPP3 in nanograms/milliliter)

patients. The association between DPP3 levels, circulatory failure, and AKI is consistent with the current understanding of AKI in the critically ill, associating hemodynamic factors and inflammation/immune response $[19,20]$. These results might also be expected in patients developing systemic inflammatory response from different causes (e.g., sepsis, post-cardiopulmonary bypass, post-cardiac arrest, pancreatitis), and it should be further explored.

In the current study, DPP3 was strongly associated with mortality and hemodynamic failure, even after adjustment for classic markers of severity and prognosis.

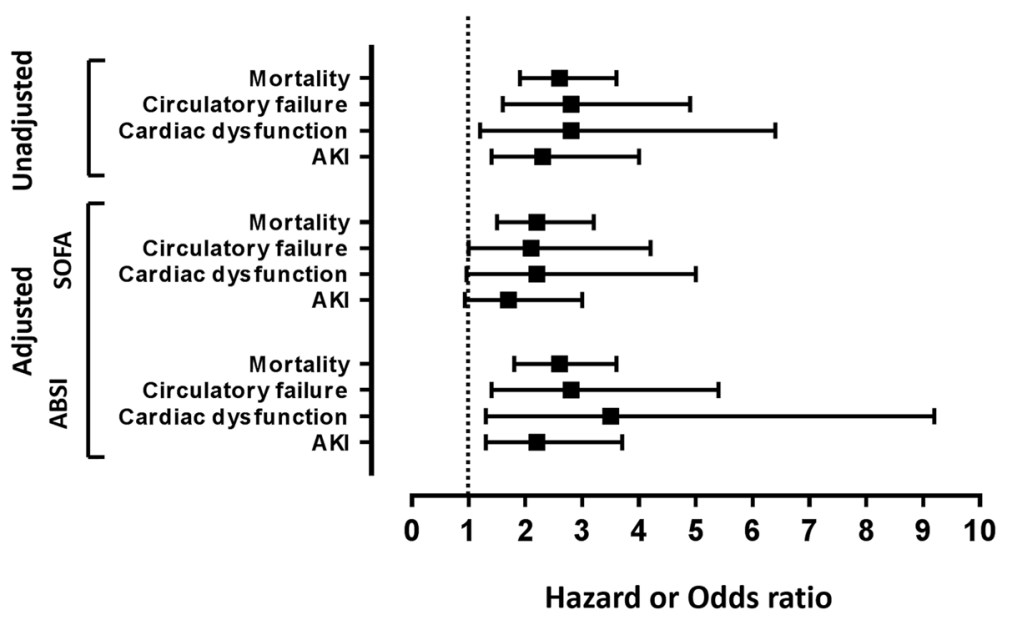

Fig. 2 Represents unadjusted and adjusted (i.e., on Sequential Organ Failure Assessment-SOFA-OFA score or Abbreviated Burn Severity IndexABSI) hazard ratio (HR) and/or odds ratio (OR) of DPP3 admin value and outcomes (i.e., mortality, cardiac dysfunction, circulatory failure and acute kidney injury, AKI, respectively). Mortality $n=111 / 36$ events, HR not adjusted HR=2.6 (1.9-3.6); adjusted on SOFA score, HR=2.2 (1.5-3.2); and adjusted on $\mathrm{ABSI}, \mathrm{HR}=2.6(1.8-3.6)$, respectively. Circulatory failure, $n=111 / 53$ events, OR not adjusted: OR = 2.8 (1.6-4.9); adjusted on SOFA score, $\mathrm{HR}=2.1$ (1.0-4.2) and adjusted on ABSI, HR=2.8 (1.4-5.4), respectively. Cardiac dysfunction, $n=59 / 10$ events, OR not adjusted: OR=2.8 (1.2-6.4); adjusted on SOFA score, $\mathrm{HR}=2.2(0.96-5.0)$ and adjusted on $\mathrm{ABSI}, \mathrm{HR}=3.5(1.3-9.2)$, respectively. Acute kidney injury (AKI) $n=111 / 35$ events, OR not adjusted: $\mathrm{OR}=2.3$ (1.4-4.0); adjusted on SOFA score, $\mathrm{HR}=1.7(0.93-3.0)$; and adjusted on $\mathrm{ABSI}, \mathrm{HR}=2.2$ (1.3-3.7), respectively 


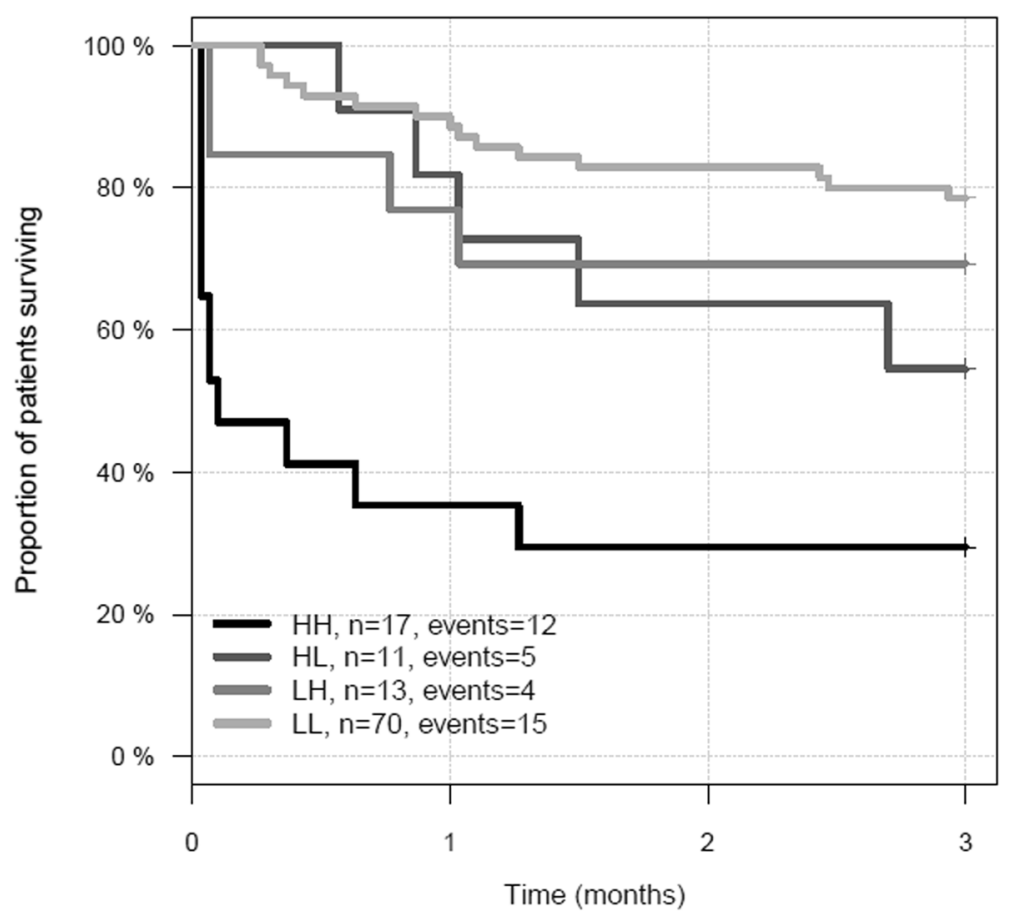

Fig. 3 Represents an illustration of the added value of DPP $3_{\text {day }}$ using a cut point of $53.65 \mathrm{ng} / \mathrm{mL}$ at admission and day 3 . Patients without DPP3 data at day 3 were left in their subgroup assigned to on day 1. High at admission and high at day $3(\mathrm{HH})$ : patients above $53.65 \mathrm{ng} / \mathrm{mL}$ at admission and at day 3; high at admission and low at day 3 (HL): patients above $53.65 \mathrm{ng} / \mathrm{mL}$ at admission and below $53.65 \mathrm{ng} / \mathrm{mL}$ at day 3 ; low at admission and high at day 3 low high (LH): patients below $53.65 \mathrm{ng} / \mathrm{mL}$ at admission and above $53.65 \mathrm{ng} / \mathrm{mL}$ at day 3 ; low at admission and low at day 3 (LL): Patients below $53.65 \mathrm{ng} / \mathrm{mL}$ at admission and on day 3. Cut point identified is the third quartile $(53.65 \mathrm{ng} / \mathrm{mL})$

Recently, Deniau et al. observed an association between high plasmatic levels of DPP3 and high mortality and organ dysfunction in severe heart failure patients. Furthermore, I.V. administration of DPP3 rapidly deteriorated cardiac contraction in mice [21]. In an ancillary study of the OptimaCC study, Takagi et al. showed that high circulating DPP3 was associated with low cardiac index, refractory shock, and high mortality in patients with cardiogenic shock [22].

The results of the present study have several potential implications for future research. First, the identification of patients with high plasma DPP3 may trigger cardiac function assessment. Second, high DPP3 levels at admission may help to select candidate patients for

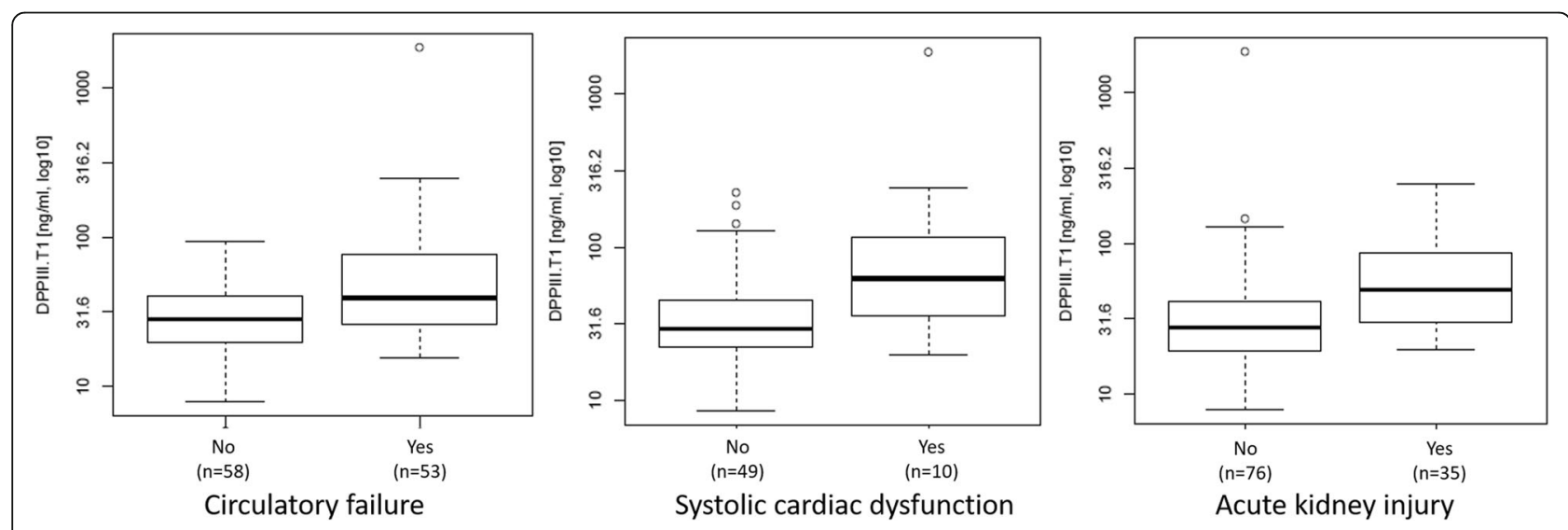

Fig. 4 Represents median DPP3 admin between patients with and without circulatory failure in the first $48 \mathrm{~h}$ (left panel), between patients with or without systolic cardiac dysfunction at admission (middle panel), and between patients with or without acute kidney injury (right panel) 
alternative vasopressor therapies, especially for infusion of angiotensin II [23, 24]. Angiotensin II has been found to be downregulated in some forms of septic shock associated with poor prognosis [25]. DPP3 cleaves angiotensin II and may, therefore, play a role in vasoplegic shock by reducing angiotensin II levels. Since angiotensin II is not easy to measure in clinical practice, DPP3 may represent a potential candidate biomarker for selecting patients most likely to respond to angiotensin II infusion. Third, pharmacological inhibition of DPP3 by a specific antibody has been shown to promptly restore and sustain cardiac contraction in mice [21] and might be a therapeutic option in burn patients with high DPP3. All these strategies are hypothesis and require exploration and validation in well-designed prospective human studies.

Our study has several limitations. First, the observational design of the present study does not allow us to conclude on the causality between DPP3 and mortality or organ dysfunction. Second, the study contains a relatively low number of patients, even though this is one of the largest cohort studies among critically ill burn patients with sufficient power to identify an association between the biomarker levels and outcomes. Thirdly, factors influencing DPP3 metabolism are unknown and will need further exploration in critically ill burn patients. Finally, only half of our patients had an echocardiography at admission, limiting the interpretation of the association between DPP3 levels and cardiac dysfunction.

\section{Conclusion}

Plasma DPP3 concentration at admission was associated with an increased risk of death, circulatory failure, and AKI in severely burned patients. Whether DPP3 plasma levels could identify patients who would respond to alternative hemodynamic support strategies, such as intravenous angiotensin II, should be explored.

\section{Supplementary information}

Supplementary information accompanies this paper at https://doi.org/10. 1186/s13054-020-02888-5.

Additional file 1: Figure S1. represents interaction between Total Body Surface Area (TBSA) and DPP3 $3_{\text {admin }}$ (TIF $43 \mathrm{~kb}$ )

Additional file 2. Supplementary data Table 1. Patients characteristics according to TBSA (Total burn surface area).

\footnotetext{
Abbreviations

DPP3: Dipeptidyl peptidase-3; AKI: Acute kidney injury; ICBU: Intensive care burn unit; TBSA: Total body surface area burn; BMI: Body mass index; BSA: Body surface area; ABSI: Abbreviated Burn Severity Index; UBS: Unit Burn Standard; SOFA: Sequential Organ Failure Assessment; LVEF: Left ventricular ejection fraction; KDIGO: Kidney Disease: Improving Global Outcomes; IQR: Interquartile range; HR: Hazard ratio; OR: Odds ratio; ROC: Receiver operator characteristics
}

\section{Acknowledgments}

The paramedical staff of Burn Intensive Care unit of Saint-Louis hospital for their active participation to the protocol. We thank the Clinical Research Assistants, Marie-Céline Fournier, and Elisabeth Cerrato from the joint research unit HCL/bioMérieux for the technical assistance with the samples.

\section{Authors' contributions}

FD collected the data, contributed to the interpretation of the data, and drafted the manuscript. AP collected the data, contributed to the interpretation of the data, and drafted the manuscript. JA collected the data, contributed to the interpretation of the data, and drafted the manuscript. LFP collected the data, contributed to the interpretation of the data, and drafted the manuscript. MCo collected the data, contributed to the interpretation of the data, and drafted the manuscript. MCh collected the data, contributed to the interpretation of the data, and drafted the manuscript. KS performed DPP3 measurements, contributed to the interpretation of the data, and drafted the manuscript. OH performed analysis and contributed to the interpretation of the data, and drafted the manuscript. MJ collected the data, contributed to the interpretation of the data, and drafted the manuscript. AF collected the data, contributed to the interpretation of the data, and drafted the manuscript. $\mathrm{HO}$ collected the data, contributed to the interpretation of the data, and drafted the manuscript. AC collected the data, contributed to the interpretation of the data, and drafted the manuscript. MB collected the data, contributed to the interpretation of the data, and drafted the manuscript. LG collected the data, contributed to the interpretation of the data, and drafted the manuscript. BD collected the data, contributed to the interpretation of the data, and drafted the manuscript. AM conceived the study, contributed to the interpretation of the data, and drafted the manuscript. BF collected the data, contributed to the interpretation of the data, and drafted the manuscript. JT collected the data, contributed to the interpretation of the data, and drafted the manuscript. ML conceived the study, contributed to the interpretation of the data, and drafted the manuscript. The authors read and approved the final manuscript.

\section{Funding}

This study was supported by a grant from the "Association des Gueules cassées" to Matthieu Legrand. Measurement of DPP3 was funded by 4TEEN4 Pharmaceuticals GmbH.

\section{Availability of data and materials}

The datasets used and/or analyzed during the current study are available from the corresponding author on reasonable request.

Ethics approval and consent to participate

The study protocol was approved by our local research ethical committee (Comité de Protection des Personnes 2013/17NICB).

\section{Consent for publication}

Not applicable.

\section{Competing interests}

FD has received research grants from the French ministry of health, Société française d'anesthésie reanimation, European Society of Intensive Care Medicine, and lecture fees Sedana medical.

JA has no conflict of interest.

MCo has no conflict of interest.

MCh has no conflict of interest.

$\mathrm{KS}$ and $\mathrm{OH}$ are employed by 4TEEN4 Pharmaceuticals $\mathrm{GmbH}$, a company which holds patent rights in and commercializes the DPP3 assay.

MJ has no conflict of interest.

AF has no conflict of interest.

$\mathrm{HO}$ has no conflict of interest.

AC has no conflict of interest.

$\mathrm{MB}$ has no conflict of interest.

LG has no conflict of interest.

$\mathrm{BD}$ received research grant from 4TEEN4 Pharmaceuticals $\mathrm{GmbH}$. AM has received speaker's honoraria from Novartis, Orion, and Servier and fees as a member of the advisory board and/or steering committee from Cardiorentis, Adrenomed, sphingotec, Sanofi, Roche, Abbott, and BristolMyers Squibb. 
BS has no conflict of interest.

$\mathrm{JT}$ is employed by Biomerieux.

$M L$ has received research grants from the French ministry of health, lecture fees from Baxter, and Fresenius and research support from Sphingotec.

\section{Author details}

'Department of Anesthesiology and Critical Care and Burn Unit, AP-HP, GH St-Louis-Lariboisière, Paris, France. ${ }^{2}$ University Paris Diderot, Paris, France. ${ }^{3}$ UMR INSERM 942, Institut National de la Santé et de la Recherche Médicale (INSERM), F-CRIN INICRCT network, Paris, France. ${ }^{4}$ Department of Anesthesiology and Critical Care, Burn Center Pierre Colson, Hospices Civils de Lyon, Edouard Herriot Hospital, Lyon, France. ${ }^{5}$ 4TEEN4 Pharmaceuticals $\mathrm{GmbH}$, Hennigsdorf, Germany. ${ }^{6} \mathrm{EA} 7426$ Pathophysiology of Injury-induced Immunosuppression, University of Lyon1-Hospices Civils de Lyon-bioMérieux, Hôpital Edouard Herriot, Lyon, France. ${ }^{7}$ Department of Anesthesia and Perioperative Care, UCSF Medical Center, University of California, 500 Parnassus Avenue MUE416, Box 0648, San Francisco, CA 94143, USA.

Received: 20 February 2020 Accepted: 13 April 2020

Published online: 22 April 2020

\section{References}

1. Soussi S, Dépret F, Benyamina M, Legrand M. Early hemodynamic management of critically ill burn patients. Anesthesiology. 2018;129:583-9.

2. Soussi S, Deniau B, Ferry A, Levé C, Benyamina M, Maurel V, et al. Low cardiac index and stroke volume on admission are associated with poor outcome in critically ill burn patients: a retrospective cohort study. Ann Intensive Care. 2016;6:87.

3. Soussi S, Taccori M, De Tymowski C, Depret F, Chaussard M, Fratani A, et al. Risk factors for acute mesenteric ischemia in critically ill burns patients-a matched case-control study. Shock. 2019;51:153-60.

4. Bak Z, Sjöberg F, Eriksson O, Steinvall I, Janerot-Sjoberg B. Cardiac dysfunction after burns. Burns. 2008;34:603-9.

5. Zhan H, Yamamoto Y, Shumiya S, Kunimatsu M, Nishi K, Ohkubo I, et al. Peptidases play an important role in cataractogenesis: an immunohistochemical study on lenses derived from Shumiya cataract rats. Histochem J. 2001;33:511-21.

6. Prajapati SC, Chauhan SS. Dipeptidyl peptidase III: a multifaceted oligopeptide N-end cutter: dipeptidyl peptidase III. FEBS J. 2011;278: 3256-76.

7. Pang X, Shimizu A, Kurita S, Zankov DP, Takeuchi K, Yasuda-Yamahara M, et al. Novel therapeutic role for dipeptidyl peptidase III in the treatment of hypertension. Hypertension. 2016;68:630-41.

8. Dale CS, Pagano R de L, Rioli V. Hemopressin: a novel bioactive peptide derived from the a1-chain of hemoglobin. p. 2. https://doi.org/10.1590/ s0074-02762005000900017.

9. Tobiasen J, Hiebert JM, Edlich RF. The abbreviated burn severity index. Ann Emerg Med. 1982;11:260-2.

10. Bull JP, Squire JR. A study of mortality in a burns unit: standards for the evaluation of alternative methods of treatment. Ann Surg. 1949;130:160.

11. Vincent JL, Moreno R, Takala J, Willatts S, De Mendonça A, Bruining H, et al. The SOFA (Sepsis-related Organ Failure Assessment) score to describe organ dysfunction/failure. On behalf of the working group on sepsis-related problems of the European Society of Intensive Care Medicine. Intensive Care Med. 1996;22:707-10.

12. Soussi S, Dépret F, Benyamina M, Legrand M. Anesthesiology. 2018;129(3): 583-9. https://doi.org/10.1097/ALN.0000000000002314.

13. Rich S, Sheikh A, Gallastegui J, Kondos GT, Mason T, Lam W. Determination of left ventricular ejection fraction by visual estimation during real-time two-dimensional echocardiography. Am Heart J. 1982;104:603-6.

14. Kellum JA, Lameire N, For the KDIGO AKI guideline work group. Diagnosis, evaluation, and management of acute kidney injury: a KDIGO summary (part 1). Crit Care. 2013;17:204.

15. Rehfeld L, Funk E, Jha S, Macheroux P, Melander O, Bergmann A. Novel methods for the quantification of dipeptidyl peptidase 3 (DPP3) concentration and activity in human blood samples. J Appl Lab Med. 2019; 3:943-53.

16. Greenhalgh DG. Management of burns. N Engl J Med. 2019:380:2349-59.

17. Jeschke MG, Pinto R, Kraft R, Nathens AB, Finnerty CC, Gamelli RL, et al. Morbidity and survival probability in burn patients in modern burn care. Crit Care Med. 2015;43:808-15.
18. Legrand M, Guttormsen AB, Berger MM. Ten tips for managing critically ill burn patients: follow the RASTAFARI! Intensive Care Med. 2015:41:1107-9.

19. Ronco C, Bellomo R, Kellum JA. Acute kidney injury. Lancet Lond Engl. 2019; 394:1949-64.

20. Wong BT, Chan MJ, Glassford NJ, Mårtensson J, Bion V, Chai SY, et al. Mean arterial pressure and mean perfusion pressure deficit in septic acute kidney injury. J Crit Care. 2015;30:975-81.

21. Deniau B, Rehfeld L, Santos K, Dienelt A, Azibani F, Sadoune M, Kounde PR, Samuel JL, Tolpannen H, Lassus J, Harjola VP, Vodovar N, Bergmann A, Hartmann O, Mebazaa A, Blet A. Eur J Heart Fail. 2020;22(2):290-9. https:// doi.org/10.1002/ejhf.1601.

22. Takagi K, Blet A, Levy B, Deniau B, Azibani F, Feliot E, Bergmann A, Santos K, Hartmann O, Gayat E, Mebazaa A, Kimmoun A. Eur J Heart Fail. 2020;22(2): 279-86. https://doi.org/10.1002/ejhf.1600.

23. Chow JH, Abuelkasem E, Sankova S, Henderson RA, Mazzeffi MA, Tanaka KA Reversal of vasodilatory shock: current perspectives on conventional, rescue, and emerging vasoactive agents for the treatment of shock. Anesth Analg. 2020;130:15-30.

24. Khanna A, English SW, Wang XS, Ham K, Tumlin J, Szerlip H, et al. Angiotensin II for the treatment of vasodilatory shock. N Engl J Med. 2017; 377:419-30.

25. Wakefield BJ, Sacha GL, Khanna AK. Vasodilatory shock in the ICU and the role of angiotensin II. Curr Opin Crit Care. 2018;24:277-85.

\section{Publisher's Note}

Springer Nature remains neutral with regard to jurisdictional claims in published maps and institutional affiliations.
Ready to submit your research? Choose BMC and benefit from:

- fast, convenient online submission

- thorough peer review by experienced researchers in your field

- rapid publication on acceptance

- support for research data, including large and complex data types

- gold Open Access which fosters wider collaboration and increased citations

- maximum visibility for your research: over $100 \mathrm{M}$ website views per year

At BMC, research is always in progress.

Learn more biomedcentral.com/submissions 